\title{
Gestão de recursos humanos: teorias e práticas
}

MARIA JOÃO NICOLAU SANTOS*

\section{Introdução}

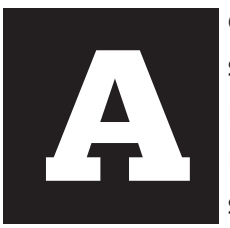

emergência de uma sociedade do conhecimento, o desenvolvimento das tecnologias de informação e conhecimento (TIC) e os processos de globalização inequivocamente alteraram a forma como ao longo de várias décadas se exerceu a gestão empresarial.

Em presença de uma economia crescentemente global, em rápida mutação e orientada para a especificidade de cada cliente em particular, as empresas têm de possuir uma maior flexibilidade e capacidade de inovação como condição sinequanon para se manterem competitivas. Isto leva os agentes económicos a requerer uma maior flexibilização na gestão do factor trabalho e dos seus custos e uma maior diversificação das relações intra e interorganizacionais.

Com a emergência de uma sociedade do conhecimento, a produção de bens não tangíveis assume um peso crescente na economia. O conhecimento está integrado numa proporção crescente em todas as actividades, dado que a produção de um bem ou serviço incorpora cada vez mais informação e conhecimento. O conhecimento surge assim como um valor económico em si que importa gerir de forma eficiente.

* Doutoramento em Sociologia Económica. Professora Auxiliar do Instituto Superior de Economia e Gestão (ISEG) da Universidade Técnica de Lisboa (UTL), Portugal. 
Estas alterações têm tido profundas implicações no padrão de competitividade. As vantagens competitivas deixam de estar associadas aos factores tradicionais (preço das matérias-primas, energia, trabalho), para dependerem de um modelo dinâmico assente na capacidade de inovação, seja ela dos processos produtivos, produtos/serviços, estruturas e redes relacionais, como também do acesso a determinados recursos estratégicos como sejam as competências humanas, sinergias de mudança, a informação ou serviços de apoio.

Relativamente às formas de concorrência, verificou-se que o desenvolvimento das TIC e da globalização desencadeou não apenas um aumento de concorrência, decorrente do aparecimento de novos países produtores e da intensificação da concorrência entre os países da tríade (EUA, Europa, Japão e outros países asiáticos), mas deu sobretudo origem ao surgimento de novos mecanismos de concorrência. Com o estabelecimento de alianças estratégicas, as empresas deixaram de concorrer isoladamente no mercado, mas passaram a fazê-lo enquadradas em parcerias, mudando significativamente o modo como o mercado funciona. Deste modo, as regras de concorrência passaram a ser determinadas no contexto de redes profundamente globalizadas.

Foi em presença deste novo quadro competitivo, marcado como foi supra referido, pela alteração das formas de concorrência, mutabilidade, crescente inovação e importância do conhecimento, que as empresas tiveram necessidade de se reestruturar. Neste sentido, as empresas tiveram de alterar as suas formas de organização produtiva e de desenvolver novos modelos de gestão interna, assentes numa maior flexibilidade e em estruturas em rede.

\section{Matriz teórica}

Em termos teóricos, parte-se do princípio que perante um contexto em que a criação de valor depende sobretudo da capacidade para desen- 
volver novos produtos/serviços com maior valor acrescentado, isto é, com maior incorporação de conhecimento, as empresas devem criar condições internas que permitam estimular a inovação e a criatividade. É através da criatividade, da inovação e da aplicação do conhecimento que se podem criar, desenvolver e produzir produtos/serviços com maior valor acrescentado (Silva; Neves 2003). A capacidade de saber produzir conhecimento, de saber geri-lo eficazmente está assim na base da criação de riqueza.

Saber gerir conhecimento significa concentrar-se nos processos de criação, armazenamento, partilha e distribuição de conhecimento (Bontis, 2002; Choo, 2000). Significa criar um conjunto de condições que permita desenvolver o capital intelectual de uma empresa.

De que forma é que as empresas podem fazê-lo? Teoricamente existe algum consenso de que o podem fazer essencialmente por três vias:

\section{1 - desenvolvendo o capital humano}

Isto significa desenvolver as competências individuais. Para isso não basta um acréscimo de formação. É necessário uma mudança de atitude no sentido do desenvolvimento de recursos humanos com maior grau de responsabilização, orientados não apenas para o cumprimento de objectivos e índices de performance, previamente negociados e ancorados na orientação estratégica da empresa, mas igualmente com uma crescente autonomia e liberdade de acção, condições indispensáveis para o desenvolvimento de actos criativos.

\section{2 - desenvolvendo o capital estrutural}

Pressupõe a concepção de estruturas que estimulem a aprendizagem interna ao nível de toda a empresa. Isto significa, não apenas a capacidade para estimular a iniciativa e a criatividade individual, referida anteriormente, mas o reforço das redes pessoais, relacionais e informacionais que promovam a difusão do conhecimento intra organizacional, contribuindo para aprendizagem do todo. 


\section{3 - desenvolvendo capital relacional}

Isto implica desenvolver permutas de informação e conhecimento com o exterior. O conhecimento mais valioso resulta/depende da interacção entre diferentes pessoas e organizações. A inovação é um processo cumulativo de aprendizagem dependendo cada vez menos de cada empresa isoladamente e mais das interacções que estabelece com o exterior.

A importância que teoricamente é atribuída ao desenvolvimento do capital intelectual (Stewart, 1999 e 2002) requer uma análise mais detalhada de cada uma destas três dimensões que o integram.

\subsection{Capital Humano}

Um dos desafios mais exigentes a que as empresas têm de responder é a desenvolver as competências humanas internas. De que forma podem fazê-lo:

A) Promovendo recursos humanos qualificados

Tradicionalmente as empresas investem em formação como instrumento privilegiado para o desenvolvimento das qualificações. Todavia, tendo em conta as exigências a que as empresas estão submetidas já não é por si só suficiente a existência de qualificações relacionadas com o exercício de uma determinada profissão. Já não basta ter recursos humanos qualificados. É necessário que estes disponham de um amplo leque de competências que lhes permitam criar e inovar, e que tenham capacidade para aprender, pensar e saber valorizar as suas contribuições.

Um trabalhador do conhecimento é aquele que sabe seleccionar, absorver informação e conhecimento onde quer que ele se encontre e com capacidade para aplicar este conhecimento em acções concretas (HBR 2000). 
Deste modo, a formação tende a ser encarada menos como um conjunto de saberes cristalizados e transmitidos internamente, mas sobretudo, como um amplo conjunto de instrumentos (bases de dados, estudos, relatórios, informações diversas, conhecimentos, técnicas) que a empresa coloca à disposição dos seus recursos humanos, possibilitando a cada um a sua ampla utilização, de acordo com as suas necessidades e segundo uma lógica de auto-aprendizagem.

Significa portanto o proporcionar as ferramentas necessárias e a disponibilização conteúdos que sejam adequados a um amplo exercício das funções requeridas. Deve constituir um suporte informacional a partir do qual os recursos humanos podem desenvolver as suas competências e colocálas ao serviço da organização.

Isto pressupõe uma alteração significativa no modo como a formação é concebida. Esta deixa de ser pensada como algo definido exteriormente, mas passa a estar inscrita num quadro de auto-formação, de auto-desenvolvimento pessoal. Obviamente que esta alteração requer a existência de uma grande maturidade racional e emocional, diria antes uma elevada maturidade intelectual, que permita que cada um individualmente alargue e aprofunde as suas competências e as oriente para acções criativas. Acções não espontâneas, mas organizadas e inscritas nas orientações estratégicas (visão, missão, objectivos) das unidades funcionais em que estão inseridas e da empresa no seu todo.

B) Criando ambientes que estimulem a auto-aprendizagem

O que foi anteriormente referido só se consegue através da criação de um ambiente que permita e que estimule auto-aprendizagem. É importante que no exercício das actividades do quotidiano as pessoas tenham, em termos de tempo e de espaço, condições que permitam o desenvolvimento das suas competências.

É um facto que o processo de criação de conhecimento requer ambientes que estimulem a criatividade, a autonomia, a liberdade de pensa- 
mento (Amabile, 1998).O desafio é considerar a criatividade como parte integrante e estratégica da filosofia da própria empresa. Para isso torna-se necessário identificar os factores que bloqueiam este acto criativo. Geralmente estão relacionados com o excesso de rotina, com tarefas rigidamente estruturadas, com isolamentos interdepartamentais, falhas de comunicação, processos burocráticos e procedimentos demasiado rígidos. O excessivo dirigismo constitui também um elemento disfuncional, e conjuntamente com os aspectos referidos, impedem uma maior transversalidade das relações e ambientes mais fluidos, mais ricos em termos de troca de informações. A identificação das barreiras e a sua desobstrução constitui um importante passo para a criação de ambientes mais propícios ao desenvolvimento das competências humanas e à expressão da sua criatividade.

C) Gerindo adequadamente as pessoas

Tendo em conta que quase todo o conhecimento reside nas pessoas ou ainda que a sua potenciação delas depende, urge gerir as pessoas em conformidade com este pressuposto. Esta constatação, por si só evidente, pressupõe uma reorganização no modo de gestão das pessoas.

Implica pensar as pessoas como geradoras de conhecimento, com potencialidades e competências que devem ser direccionadas e colectivamente organizadas. Conduzir as pessoas a realizar o seu potencial significa saber gerir os recursos humanos com inteligência, sensibilidade e flexibilidade e requer a atribuição de uma maior liberdade e responsabilidade na gestão das pessoas.

Isto pressupõe igualmente uma reorientação nas práticas de gestão. Pressupõe a adopção de um estilo de gestão que governa com base na gestão das emoções, na criação de empatia e de estados de sintonia, requisitos que vão muito para além de uma gestão puramente racional (centrada em objectivos), mas pressupõe uma capacidade para gerir a componente emocional das pessoas (Goleman, Boyatzis, Mackee, 2002). 
D) Estimulando o desenvolvimento de comunidades intelectuais

Outro instrumento importante para o desenvolvimento do capital humano é o reconhecimento e fortalecimento de comunidades intelectuais (Silva; Neves, 2003). As comunidades de prática não são mais do que grupos informais, frequentemente transversais relativamente à estrutura formal, onde privilegiadamente se trocam e partilham informações dando origem a um processo cumulativo de aprendizagem. Importa reforçar a ideia de que a aprendizagem e sobretudo a inovação não resulta de actos individualizados, mas é uma actividade socialmente construída e decorre de um processo colectivamente construído no decursos de interacções várias.

A promoção de comunidades intelectuais, isto é, de grupos relacionais geralmente de carácter informal (paralelamente aos grupos de trabalho formalmente instituídos) são um instrumento de troca e partilha de experiências. Constituem-se como elemento multiplicador de aprendizagens, e como tal o seu desenvolvimento é igualmente um acto de gestão fundamental, do qual depende a aprendizagem organizacional.

O facto destes grupos terem geralmente um carácter informal, dificilmente visíveis, torna a sua promoção ainda mais difícil não sendo por isso passíveis de serem geridos no sentido tradicional. Contudo, mais importante do que tentar identificá-los ou defini-los, é saber criar as condições para que se formem e se consolidem. Isto pressupõe que em primeiro lugar se lhes reconheça importância que realmente eles possuem e que se disponibilizem os recursos de que necessitam de modo a facilitar o seu desenvolvimento. Criar sistemas de comunicação intra e interorganizacionais, estimular a mobilidade de trabalhadores para que possam trocar experiências, são alguns dos mecanismos que podem ter um efeito potencializador, interferindo-se o menos possível. 


\subsection{Capital Estrutural}

Acresce ainda que apesar do desenvolvimento dos recursos humanos em termos das suas competências individuais ser fundamental, por si só não é suficiente. O importante é que as competências individuais estejam articuladas e contribuam para o desenvolvimento da organização enquanto entidade autónoma, isto é, que permita a aprendizagem do conjunto do todo organizacional (Argyris, 1994).

Visível através do conhecimento acumulado, a competência que a organização no seu conjunto adquiriu não reside na(s) pessoa(as), mas da dinâmica que o colectivo consegue imprimir. A produtividade do capital intelectual depende da partilha e da capacidade da organização em transformá-lo em projectos, produtos/serviços transaccionáveis no mercado. Neste sentido, importa converter o conhecimento especializado do colaborador em performance empresarial.

Para isso é necessário uma partilha rápida do conhecimento, um crescimento do conhecimento colectivo traduzível numa redução do tempo de resposta, na capacidade de inovação/desenvolvimento dos produtos ou serviços. De que forma podem fazê-lo:

A) Orientação para acções colectivamente enquadradas

Isto significa a necessidade de se contextualizar o trabalho entre as diversas pessoas e de o articular com a estratégia da organização. Pressupõe a promoção do relacionamento entre as pessoas e envolvimento de todos num projecto comum, devidamente enquadrado na missão e objectivos da organização.

A sua concretização pressupõe a adopção de um conjunto de medidas, nomeadamente (Stewart, 1999):

a) a necessária definição de orientações estratégicas e difusão das mesmas de modo a se conseguir a polarização de todos em torno de um projecto comum; 
b) a clara definição de níveis de envolvimento e responsabilidade;

c) o estimulo à intervenção de todos na equação das dificuldades e na implementação de soluções conjuntas;

d) a criação de um ambiente com qualidade em termos de estímulos;

e) o envolvimento colectivo, de modo que as pessoas sintam a organização como sua.

Estes são alguns aspectos parcelares que integram um objectivo mais amplo: a capacidade e a responsabilidade para contextualizar o trabalho das diferentes pessoas e para as orientar colectivamente para o cumprimento dos objectivos definidos. O que está de facto em causa é a capacidade para se estabelecer uma adequada ligação entre o capital intelectual e a estratégia organizacional.

\section{B) Gerindo conhecimento}

Como foi anteriormente referido, no contexto de uma economia do conhecimento o conhecimento existente e a produzir tem de ser considerado como o activo mais importante de uma empresa. Com tal deve ser utilizado como um instrumento de gestão estrategicamente relevante.

A criação de redes a escolha de uma metodologia de intervenção constituem instrumentos de gestão essenciais (Bontis, 2002). A gestão do conhecimento pressupõe a existência de especialistas que possam identificar áreas, domínios e actividades a partir do qual se possa fazer uma gestão eficaz de todo este processo. A criação de redes relacionais e informacionais que permitam estabelecer a ligação entre pessoas, aceder a dados e informações relevantes (de forma a acelerar o fluxo de criação e de difusão do conhecimento), e a criação de stocks de conhecimento, por via da construção de bases de dados on-line, com a informação e o conhecimento disponível para que cada pessoa possa aceder sempre que necessário, são algumas dos instrumentos utilizados (Choo; Bontis, 2000). 


\section{C) Criando estruturas em rede}

Para que exista transferência de conhecimento de um cérebro para outro, para que exista um processo organizado e cumulativo de inovação não basta existir bases de dados, sistemas comuns de partilha de informação (Clark, 2001). É necessário que a cultura instituída e as estruturas permitam a articulação entre as diversas áreas departamentais, grupos de projectos, pessoas, etc. É necessário que se crie uma inteligência partilhada, uma rede conjunta de relações, de fluxos de informações de trocas de ideias e conceitos que promovam o desenvolvimento do colectivo. Neste contexto, a tradicional estrutura organizacional tende a ser suplantada por uma rede relacional, circuitos transversais, impulsos... Mais importante que ter uma estrutura e uma cadeia de comando claramente definida é ter uma inteligência partilhada, ancorada em fortes redes relacionais.

Estas redes são mais amplas do que as redes institucionalizadas muitas vezes apresentadas sob forma de equipas de trabalho transversais. São antes ligações sociais, redes de relacionamento, as quais frequentemente extravasam o próprio espaço da empresa.

\subsection{Capital relacional}

Deste modo, a maximização do capital intelectual resulta igualmente da capacidade de as empresas absorverem a complexidade externa (Stewart, 1999). O exterior é particularmente rico em estímulos que devem ser aproveitados e potencializados. Além disso, importa estar consciente que no actual enquadramento, o conhecimento mais valioso decorre da interacção entre diferentes pessoas ou organizações e que o valor económico se centra na qualidade destas interacções e na operacionalidade das redes construídas.

Neste sentido, torna-se crucial o estabelecimento de interacções múltiplas. O diálogo com os vários stakeholders, a realização de parcerias com outras unidades para desenvolvimento de projectos conjuntos ou o 
estabelecimento de ligações estreitas com outros parceiros de negócio, pode desencadear novas oportunidades de negócio, melhoria de serviços ou outras acções inovadoras. O importante é a capacidade de construir vantagens competitivas a partir de permutas de informação e de conhecimento com o exterior.

Para que isso aconteça, para que a complexidade se expanda e frutifique é necessário viver em rede, assumindo a rede como a uma forma própria de vida. As redes assumem contornos muitos diversificados, desde relações marcadas por transacções económicas, soluções partilhadas em termos de produtos ou negócios, cooperações, etc. As ligações externas são particularmente importantes em actividades que requeiram uma forte componente de informação/conhecimento.

\section{Matriz empírica}

Depois de identificados os principais pressupostos teóricos em que assenta o discurso gestionário dominante, importa fazer uma breve reflexão sobre as práticas realmente desenvolvidas pelas empresas. Sendo certo que as estratégias empresariais não põem em causa esta bordagem teórica, a análise da realidade mostra igualmente que estes princípios estão longe de serem generalizados. Pelo contrário, eles são aplicados a um número muito restrito de pessoas e de situações concretas.

A flexibilização que as empresas imprimiram na sua gestão não segue uma via única de crescente valorização e desenvolvimento dos seus recursos humanos, como fonte de vantagem competitiva. Seguem antes uma multiplicidade de estratégias que incorporam orientações contrárias, consoante a natureza e tipologia das actividades desenvolvidas internamente.

A necessária flexibilidade procurada internamente tem sido obtida por via de uma crescente segmentação dos recursos humanos. Já nos em meados dos anos 80 Atkinson referia este movimento, o qual se tem vindo a reforçar de forma muito significativa na actualidade. 
Assim sendo, as empresas tendem a estruturarem-se de modo segmentado consoante o tipo de flexibilidade de que necessitam. Criam um núcleo central que integra as pessoas relacionadas com as actividade core da empresa. Este é composto por trabalhadores altamente qualificados, com maior estabilidade de emprego e são objecto de uma flexibilidade funcional. Em torno deste grupo formam dois outros grupos periféricos que integram trabalhadores com competências diversas consoante as necessidades. Estes estão direccionados para actividades não nucleares da empresa e constituem um mercado secundário de emprego permitindo uma flexibilidade quantitativa.

Paralelamente a este tipo de segmentação verifica-se ainda um outro movimento, o da segmentação dos recursos humanos consoante o valor acrescentado que trazem para a empresa e o grau de disponibilidade/acessibilidade no mercado de trabalho.

Quadro 1

\begin{tabular}{|l|l|}
\hline $\begin{array}{l}\text { D ificeis de Substituir } \\
\text { Baixo Valor A crescentado }\end{array}$ & $\begin{array}{r}\text { D ificeis de Substituir } \\
\text { Alto Valor A crescentado }\end{array}$ \\
\hline $\begin{array}{l}\text { Fáceis de Substituir } \\
\text { Baixo Valor Acrescentado atizar }\end{array}$ & encomendardo exterior \\
\hline
\end{tabular}

Fonte: Stewart, 1999, p.129

Neste sentido, poderemos identificar diferentes grupos de pessoas:

a) trabalhadores facilmente substituíveis e com baixo valor acrescentado para a empresa. Tendo em conta que este grupo não contribui de forma directa para a actividade nuclear da empresa, encontra-se facilmente disponível no mercado de trabalho e o seu tempo de formação é curto, então as empresas procuram, sempre que possível, automatizar estas actividades ou exteriorizá-las. 
b) trabalhadores facilmente substituíveis e com elevado valor acrescentado. Quando se trata de actividades com um grau de complexidade e especialização elevado, não directamente relacionado com as actividades core, as empresas, tendem a recrutar no exterior.

c) trabalhadores difíceis de substituir mas que têm baixo valor acrescentado para a empresa. Neste caso, como não se podem substituir facilmente ou exteriorizar, tenderá a haver uma incorporação de novas actividades paralelas.

d) trabalhadores com elevado valor acrescentado e difíceis de substituir. Considera-se que neste grupo estão integradas as pessoas que acrescentam valor por via de uma participação activa no processo de criação ou desenvolvimento de produtos/serviços.

A procura de uma crescente flexibilidade na gestão dos recursos humanos tem conduzido as empresas a segmentar os diferentes tipos de trabalhadores e a geri-los de forma igualmente diferenciada. Os trabalhadores de menor valor acrescentado, tendem a ser geridos de modo convencional ou externalizados.

É sobretudo ao nível do grupo com maior valor acrescentado que as empresas procuram capitalizar e promover. Neste caso, as estratégias de desenvolvimento do capital intelectual têm sido orientadas fundamentalmente para as actividades e para os recursos directamente relacionados com o core business, para as actividades que acrescentam valor.

Estamos assim perante a existência de diferentes práticas de gestão dos recursos humanos. Se por um lado, tende a haver uma gestão que potencializa o conhecimento e as competências individuais ao nível dos núcleos chave, correspondendo aos trabalhadores considerados de elevado valor acrescentado, por outro lado, os outros grupos de trabalhadores tendem a ser geridos de modo convencional ou externalizados, ficando excluídos deste processo, o qual pressupõe um desenvolvimento pessoal e profissional. 
Podemos afirmar, em síntese, que apesar da existência de um discurso dominante, devidamente ancorado em pressupostos teóricos, na realidade ele ainda tem uma implantação reduzida. Muitos destes pressupostos aplicam-se a um número restrito de pessoas tendendo a predominar uma gestão muito instrumental do elemento humano.

\section{Referências:}

AMABILE, Teresa; BURNSIDE, Robert; GRYSKIEWICZ, Stanley. User's manual for keys: assessing the climate for creativity. Greensboro, N.C.: Center for Creative Leadership, 1998.

ARGYRIS, Chris. On organizational learning. Oxford: Blacwell Business. 1994.

BARATA, José Monteiro. Inovação nos serviços: sistemas e tecnologias de informação e competitividade no sector bancário. 1995. Dissertação (Doutoramento) Instituto Superior de Economia e Gestão, Universidade Técnica de Lisboa, Lisboa.

BAUMARD, Philippe. Tacit knowledge in organizations. London: Sage Publications, 1999. 264 p.

BONTIS, Nick; CHOO, Wei Chun. The strategic management of intellectual capital and organizational knowledge. New York: Oxford University Press, 2002.

BUKOWITZ, Wendi; WILLIAMS, Ruth. The knowledge management fieldbook. London: Financial Times, 2000. 372 p.

CERDEIRA et al. As novas modalidades de emprego. Lisboa: Ministério do TrabaIho e da Solidariedade, 2000. 286 p.

CHOO, Chun Wei. A organização do conhecimento. São Paulo: Editora Senac, 2003. 425 p.

CHOO, Chun Wei. Gestão de Informação para a organização inteligente. Lisboa: Editorial Caminho, 2003. 365 p. 
CLARKE, Steve. Information systems strategic management. London: Routledge, 2001.

DIEKERS; ANTAL; CHILD; NONAKA. Handbook of organizational learning \& knowledge. Oxford: Oxford University Press. 2001.

EASTERBY-SMITH; LYLES, Majorie (org.). The blackwell handbook of organizational learning and knowledge managemet. Oxford: Blackwell Publishing, 2003. 676 p.

FIGALHO, Cliff; RHINE, Nancy. Building the knowledge management network. New York: Jonh Wiley \& Sons Inc, 2002. 348 p.

FILHO, Jaime Teixeira. Gerenciando conhecimento. São Paulo: Editora Senac, 2000.

GOLEMAN, Daniel. Working with emotional intelligence. New York: Batman 1998.

GOLEMAN, Daniel; BOYATSIS, Richard; McKEE, Annie. Os Novos Líderes - a inteligência emocional nas organizações. Lisboa: Gradiva, 2002. 307 p.

HARVARD BUSINESS REVIEW. Gestão do conhecimento - on knowledge management. Rio de Janeiro: Editora Campus, 2000. 205 p.

KLUGE, Jurgen; STEIN, Wolfram; LICHT, THOMAS. Gestão do conhecimento. Cascais: Princípia, 2002. 198 p.

KOVÁCS, Ilona. As metamorfoses do emprego. Oeiras: Celta Editora, 2002. 167 p.

KRUGLIANSKAS, TERRA. Gestão do conhecimento em pequenas e médias empresas. São Paulo: Negócio Editora, 2003. 375 p.

LAUDON, Kenneth C; Laudon, Jane P. Management information systems organization and technology in the networked enterprise. New Jersey: Prentice Hall Internacional, Inc., 2000.

LEIBOLD; PROBST; GIBBERT. Strategic management in the knowledge economy. London: Willey, 2002. 
McELROY, Mark. The new knowledge management: complexity, learning and sustentable innovation. London: Butterworth Heinemann, 2003.

McELROY, Mark; FIRESTONE, José. Key issues in the new knowledge management. London: Butterword Heinemann, 2003. 350 p.

PROBBST; RAUB; ROMBARDT. Managing knowledge. New York: John Willey \& Sons Lda., 1999. 360 p.

RASCÃO, José. Sistemas de informação para as organizações. Lisboa: Edições Sílabo, 2001.

SILVA, Ricardo; NEVES, Ana. Gestão de empresas na era do conhecimento. Lisboa: Edições Sílabo, 2003. 551 p.

STEWART, Thomas. A riqueza do conhecimento. Rio de Janeiro: Editora Campus, 2002. 517 p.

STEWART, Thomas. Capital intelectual. Lisboa: Edições Sílabo, 1999. 311 p.

STEWART, Thomas. The wealth of knowledge. London: Brealey Publishing, Bookwell, 2002. 379 p.

SYDANMAANLAKKA. An intelligent organization. Oxford: Capstone, 2002. 234 p.

TIWANA, Amrit. The knowledge management: toolkit. London: Ptrentice Hall, 2000.

ZORRINHO, Carlos. Gestão da informação - condição para vencer. Lisboa: Instituto de Apoio às Pequenas e Médias Empresas (IAPMEI), 1995.

Recebido: 18/06/2004

Revisado: 23/06/2004

Aceite final: 25/06/2004 


\section{Resumo}

É um facto que perante as actuais transformações sócio-económicas as empresas têm alterado significativamente o modo como gerem os recursos humanos. Todavia, ainda persiste um profundo hiato entre um discurso de gestão muito centrado na valorização do factor humano e as práticas efectivamente desenvolvidas pelas empresas.

Ao nível teórico e conceptual tem havido uma redobrada atenção quanto à importância do potencial criativo das pessoas como estratégia crucial de adaptação das empresas à mudança. Este factor surge como condição básica de sobrevivência das empresas face a um contexto altamente competitivo e profundamente incerto. A actual difusão de conceitos e teorias sobre capital intelectual, gestão do conhecimento, inteligência emocional são um exemplo claro desta redobrada importância atribuída ao elemento humano.

Contudo o funcionamento do sistema económico e social é bastante mais complexo. Evidencia uma realidade multifacetada que nem sempre se enquadra nesta abordagem conceptual, nem corresponde efectivamente às políticas empresariais veiculadas.

Em vez da tão generalizada valorização do potencial humano, verificase antes a emergência de práticas dualistas e uma segmentação dos recursos humanos no interior das empresas. Relativamente ao mercado de trabalho, apesar de frequentemente se defender uma progressiva desregulamentação, geralmente em nome de uma maior flexibilização económica e criação de emprego, o facto é que esta diversificação das relações contratuais, tem estado frequentemente associada uma crescente precarização das relações de trabalho e de emprego.

A reflexão sobre estes múltiplos movimentos e contradições entre pressupostos teóricos e as práticas concretas desenvolvidas pelas empresas serão objecto da nossa análise.

Palavras-chave: Gestão de Recursos Humanos, Capital intelectual, Gestão do conhecimento, Redes e Mercado de trabalho. 